\title{
Energy Management Strategy Based on the Driving Cycle Model for Plugin Hybrid Electric Vehicles
}

\author{
Xiaoling Fu, ${ }^{1,2}$ Huixuan Wang, ${ }^{3}$ Naxin Cui, ${ }^{1}$ and Chenghui Zhang ${ }^{1}$ \\ ${ }^{1}$ School of Control Science and Engineering, Shandong University, Jinan, Shandong 250061, China \\ ${ }^{2}$ Department of Physics, Changji University, Changji, Xinjiang 831100, China \\ ${ }^{3}$ School of Computer Science and Technology, Shandong University, Jinan, Shandong 250101, China
}

Correspondence should be addressed to Chenghui Zhang; zchui@sdu.edu.cn

Received 28 March 2014; Accepted 12 May 2014; Published 5 June 2014

Academic Editor: Qi-Ru Wang

Copyright (C) 2014 Xiaoling Fu et al. This is an open access article distributed under the Creative Commons Attribution License, which permits unrestricted use, distribution, and reproduction in any medium, provided the original work is properly cited.

\begin{abstract}
The energy management strategy (EMS) for a plugin hybrid electric vehicle (PHEV) is proposed based on the driving cycle model and dynamic programming (DP) algorithm. A driving cycle model is constructed by collecting and processing the driving data of a certain school bus. The state of charge (SOC) profile can be obtained by the DP algorithm for the whole driving cycle. In order to optimize the energy management strategy in the hybrid power system, the optimal motor torque control sequence can be calculated using the DP algorithm for the segments between the traffic intersections. Compared with the traditional charge depleting-charge sustaining (CDCS) strategy, the test results on the ADVISOR platform show a significant improvement in fuel consumption using the EMS proposed in this paper.
\end{abstract}

\section{Introduction}

The plugin hybrid electric vehicle (PHEV) has been regarded as the most promising next-generation hybrid electric vehicle (HEV) due to the advantage of lower fuel consumption, lower emission, and higher utilization rate of electrical energy. A reliable and highly efficient energy management strategy (EMS) is very critical for the realization of these advantages of PHEV. Traditional energy management strategies for PHEV can be classified into four categories: deterministic rulebased control, fuzzy rule-based control, global optimization, and real-time optimization $[1,2]$. The energy management strategy, which does not take the trip information into consideration, cannot effectively solve the problems in the hybrid power system rise on different road condition and will not really achieve comprehensive optimal performance of the vehicle as well. Therefore, the energy management strategy based on trip information has become a research focus. Deguchi et al. divided the trip into several segments and applied different strategies in these segments according to a crowded level which was determined by the local traffic condition [3]. Gong et al. built a freeway and a localroad driving cycle model based on historical traffic data and proposed a global optimal energy management strategy by solving dynamic programming [4]. A two-scale energy management strategy was presented considering the historic driving cycle model and the real-time road information simultaneously [5].

Researches aforementioned mainly dealt with the problems under standard or foreign driving cycle conditions. Nevertheless, the actual driving cycle conditions may be of great differences to the standard ones, which can lead to poor performance of the energy management strategy with respect to the standard driving cycles. Moreover, the Chinese actual road conditions, whose problems of the congestion and chaos are more serious, are also much different from the foreign road conditions. Therefore, a driving cycle model was constructed in this paper by collecting and analyzing the driving cycle data of a certain school bus in China. In order to minimize the fuel consumption, the state of charge (SOC) profile of the battery was optimized using the dynamic programming (DP) algorithm for the whole driving cycle. 
Then, taking the minimal fuel consumption as cost function to be optimized, the optimal motor torque control sequence was calculated by DP algorithm for the segments between the traffic intersections. Compared with the traditional charge depleting-charge sustaining (CDCS) strategy, the test results on the ADVISOR platform show a significant improvement in fuel consumption using EMS proposed in this paper.

\section{Realization of the EMS Based on the Driving Cycle Model}

2.1. Control System Model. To achieve the optimal distribution of energy, the future trip model is viewed as the driving cycle which is divided into $N$ segments, and the phase step is set to be 1 second. Defining SOC as the state variable and the motor torque as the control variable, the control system model can be expressed as

$$
x(k+1)=f(x(k), u(k)),
$$

where $f$ is the state transition function, $x(k)$ is the system state variable at time $k$, and $u(k)$ is the system control variable. Focusing on minimal fuel consumption, the cost function of system (1) can be written as

$$
J=\sum_{k=0}^{N-1} L[x(k), u(k)],
$$

where $L[\cdot]$ is the stage cost function, that is, the fuel consumption at the $k$ th stage. Hence, the optimal EMS for PHEV is to find an optimal control sequence $u(k)$ such that the initial state is driven to the final state, and the cost function $J$ is minimized.

2.2. Design of Energy Management Strategy. The trip modelbased EMS of plugin hybrid electric vehicles can be designed according to control model (1) and target (2). The design procedure can be expressed as follows.

(1) Build the trip model between the start point and the destination according to the historical traffic data before driving, and get the SOC trajectory using DP algorithm.

(2) Divide the whole trip into $N$ segments by the traffic signal light. The order of each segment is $p(i)(i=$ $1,2, \ldots, n)$, and $i$ denotes the index of each segment $(i=1,2, \ldots, n)$.

(3) When the vehicle enters the $i$ th segment, predict the trip model of the $(i+1)$ th segment based on the real traffic information. The SOC value at the final point of the $i$ th segment is collected as the initial value of the $(i+1)$ th segment, and the calculated SOC value at the final point of the $(i+1)$ th segment is regarded as the final value; then calculate the control sequence (motor torque sequence) $[u(0), u(1), \ldots, u(p(i)-1)]$ of the $(i+1)$ th segment by solving the DP algorithm.

(4) When the vehicle enters the $(i+1)$ th segment, take the motor torque sequence obtained in step 3 as

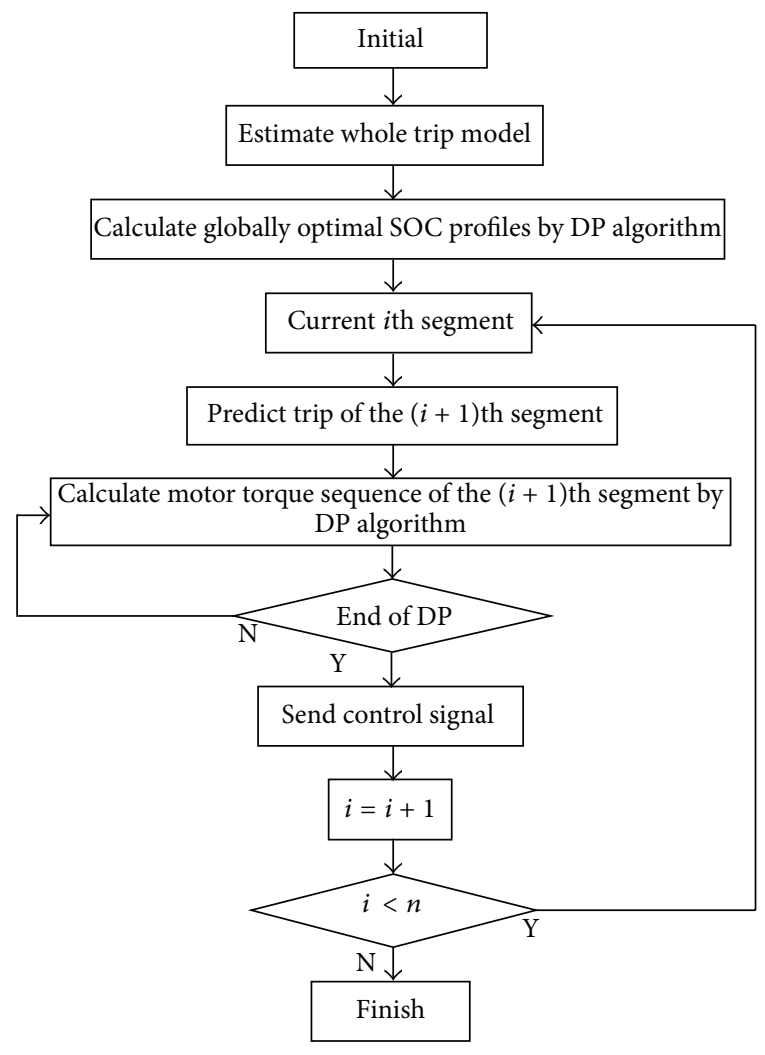

FIgURE 1: Flow chart of trip-based EMS.

the control signal, and send it to the energy management system sequently.

(5) Repeat step 3 to step 4 until the trip is over.

As mentioned above, the design process of trip-based energy management strategy of PHEV can be divided into two levels consisting of global optimization and local optimization. The future model of the whole trip is needed in order to derive the changing SOC trajectory in the global optimization, while predicting the real trip information of the next segment is necessary in the local optimization to obtain the optimal motor torque sequence of the next segment. The design procedure of this strategy is shown in Figure 1.

\section{Trip Modeling}

When designing energy management strategy, the future driving cycle model, whose parameters mainly include the travel speed, acceleration, deceleration, park time, and road slope, is needed in advance [6]. The data base in ADVISOR offers many kinds of driving cycle models, such as extra urban driving cycle (EUDC) and highway fuel economy test (HWFET). However, these driving cycles can neither stand for the trip model in China nor reflect the actual situation of the driving vehicle. Therefore, in this paper, the traffic data between the central campus and Qianfoshan Campus of Shandong University were collected at first. Then, a subtrip model of each segment was constructed and combined into a whole trip model which is the driving cycle of the school 


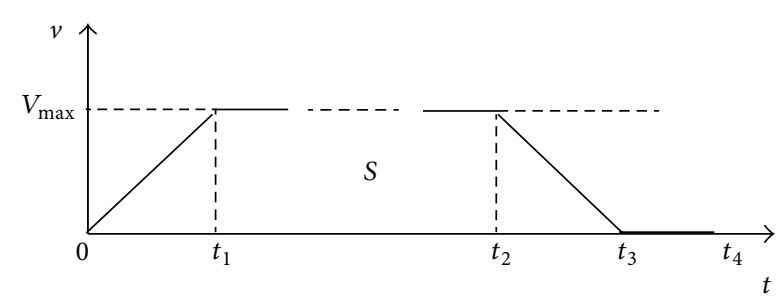

FIGURE 2: Driving cycle model.

bus. Compared with the method of using speed limit value to replace the maximum travel speed $[5,7]$, the approach adopted here is more realistic and efficient. Moreover, this method is more convenient to be popularized to the trip modeling of public and company shuttle buses which have a fixed route.

Figure 2 is the driving cycle diagram. The area of the trapezoid $S$ denotes the distance of this period, $V_{\max }$ is the maximum speed in the $i$ th segment, and $t_{1},\left(t_{2}-t_{1}\right),\left(t_{3}-\right.$ $\left.t_{2}\right)$, and $\left(t_{4}-t_{3}\right)$, denote the acceleration time, constant speed time, deceleration time, and red light waiting time, respectively. The main traffic data can be obtained through MobileMapper10 handheld GPS device, such as time, longitude, latitude, and elevation. The time-longitude/latitude information can be transformed into the time-travel speed information through an appropriate coordinate transformation [8-10]. It is found that the on/off of the red light and waiting time for the red light are highly random, so the following hypothesis should be made before modeling. The acceleration rate $a_{a}$ is equal to the deceleration rate $a_{b}$ in the same segment but is different for the different segment. It is assumed that the vehicle has to stop at every signal light and the waiting time is $25 \mathrm{~s}$. $S$ and $V_{\max }$ can be obtained by averaging the experiment data collected at the different time intervals. According to the following equation,

$$
S=\frac{1}{2} \cdot\left(\frac{V_{\max }}{a_{a}}\right)^{2} \cdot a_{a}+V_{\max } \cdot\left(t_{2}-t_{1}\right)+\frac{1}{2} \cdot\left(\frac{V_{\max }}{a_{b}}\right)^{2} \cdot a_{b}
$$

and the formula of trapezoid area

$$
S=\frac{1}{2} \cdot\left(t_{2}-t_{1}+t_{3}\right) \cdot V_{\max }
$$

$t_{1}, t_{2}, a_{a}$, and $a_{b}$ can be calculated and an individual driving cycle model for each segment is constructed. Then the whole trip model is built by connecting each segment in sequence. The driving cycle model includes traveling speed, acceleration/deceleration, and parking time, but the road slope is not taken into account. Figure 3 indicates the driving route of the school bus in Google Earth, and Figure 4 is the constructed whole trip model which contains five driving cycles.

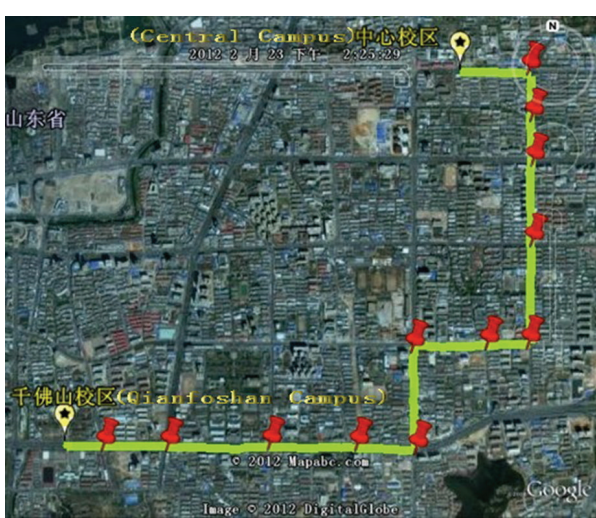

Figure 3: Driving route of the school bus from Google Earth.

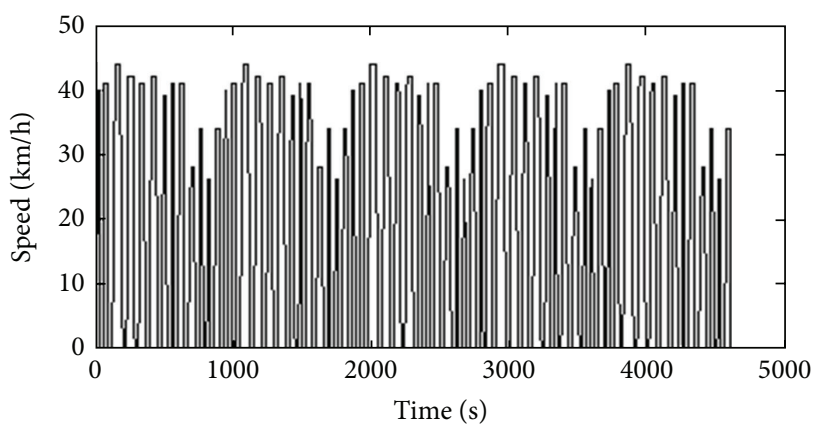

FIGURE 4: The estimated whole trip model.

\section{Constructing and Solving of the Dynamic Programming Equation}

Considering the characteristics of the plugin hybrid electric vehicle, a kind of energy management strategy called CDCS strategy is proposed, in which the vehicle works at pure electric mode firstly (the engine of the vehicle can supply power when the vehicle needs a very large torque) and changes into charger sustaining mode when the SOC decreases to a limited threshold. The CDCS strategy is convenient and suitable for PHEV, especially for a short distance case. However, trip-based energy management strategy should have much more advantages in energy saving under a long distance condition because the charge devices of electric vehicle are not widespread adopted at current time [5].

In this paper, the relationship of the engine torque, the motor torque, and the needed torque in the wheel can be expressed as

$$
T_{w}=\eta_{T} \cdot R(i) \cdot\left(T_{e}+\rho \cdot \eta_{e} \cdot T_{m}\right),
$$

where $T_{w}, T_{m}$, and $T_{e}$ are required wheel torque, motor output torque, and engine output torque, respectively, $R(i)$ is the product of the $i$ th gear speed ratio and final ratio, $\rho$ is the ratio of engine shaft and motor shaft, $\eta_{T}$ is the total transmission efficiency of gearbox and axle, and $\eta_{e}$ is the transmission efficiency from motor shaft to gearbox input shaft. 
Motor speed, engine speed, and wheel speed meet the following formula:

$$
\omega_{w}=\frac{\omega_{e}}{R(i)}=\frac{\omega_{m}}{\rho \cdot R(i)},
$$

where $\omega_{w}, \omega_{m}$, and $\omega_{e}$ are wheel speed, motor speed, and engine speed, respectively.

Ignoring the influences of internal capacitance and temperature, the state transition equation of the battery can be performed as [3]:

$$
\operatorname{SOC}(k+1)=\operatorname{SOC}(k)-\Delta \operatorname{SOC}(k),
$$

$\triangle \operatorname{SOC}(k)$

$$
=\frac{V_{\mathrm{oc}}-\sqrt{V_{\mathrm{oc}}^{2}-4\left(R_{\mathrm{int}}+R_{t}\right) \cdot T_{m}(k) \cdot \omega_{m}(k) \cdot \eta_{m}-\operatorname{sgn}\left(T_{m}(k)\right)}}{2\left(R_{\mathrm{int}}+R_{t}\right) \cdot C},
$$

where $V_{\text {oc }}$ is the open circuit voltage, $C$ is the battery capacity, $\eta_{m}$ is the motor efficiency, $R_{\text {int }}$ is the internal resistance, and $R_{t}$ stands for the terminal resistance of the battery.

The stage cost function, which consists of the fuel consumption and electric energy consumption, is defined as the equivalent fuel consumption of the $k$ th stage:

$$
P_{e}(k)=I(k) \cdot V_{\mathrm{oc}}=C \cdot(\Delta \operatorname{SOC}(k)) \cdot V_{\mathrm{oc}},
$$

where $P_{e}(k)$ is the charge/discharge power of the battery which is positive when the battery discharges and negative when the battery charges and $I(k)$ is the battery current. Consider

$$
L\left(\operatorname{SOC}(k), T_{m}(k)\right)=m_{f}(k)+\frac{s \cdot P_{e}(k)}{H_{l}},
$$

where $H_{l}$ is gasoline lower calorific value and $s$ is gasolineelectric equivalent factor. The engine fuel consumption $m_{f}(k)$ is a nonlinear function of the engine torque $T_{e}(k)$ and speed $\omega_{e}(k)$ and can be found in standard data sheet.

Usually, the gasoline-electric equivalent factor $s$ can be estimated by the average charge/discharge efficiency of the battery and the average efficiency of the engine. When the battery is discharging,

$$
s=\frac{1}{\eta_{e_{\mathrm{dis}}} \cdot \eta_{f}} .
$$

When the battery is charging,

$$
s=\frac{\eta_{e_{\text {chg }}}}{\eta_{f}}
$$

where $\eta_{f}$ is the average efficiency of engine and $\eta_{e_{\text {chg }}}$ and $\eta_{e_{\text {dis }}}$ are the charge and discharge efficiency of the battery, respectively.

Making use of the dynamic programming $[11,12]$, the cost function is constructed from (2) in order to minimize the equivalent fuel consumption in the whole trip as follows:

$$
J=\min \sum_{k=0}^{N-1} L\left(\operatorname{SOC}(k), T_{m}(k)\right)
$$

where $L$ can be seen in (9).
For the $i$ th segment, cost function (13) is constructed to minimize the equivalent fuel consumption in limited area $p(i)$ :

$$
J=\min \sum_{k=0}^{p(i)-1} L\left(\operatorname{SOC}(k), T_{m}(k)\right)
$$

For safe and smooth operation, parameters of engine, electric motor, and battery need satisfy the following inequality constraints :

$$
\begin{aligned}
& \operatorname{SOC}_{\min }(k) \leq \operatorname{SOC}(k) \leq \operatorname{SOC}_{\max }(k), \\
& \omega_{e_{\min }} \leq \omega_{e}(k) \leq \omega_{e_{\max }}, \\
& T_{e_{\min }}\left(\omega_{e}(k)\right) \leq T_{e}(k) \leq T_{e_{\max }}\left(\omega_{e}(k)\right), \\
& \omega_{m_{\min }} \leq \omega_{m}(k) \leq \omega_{m_{\max }}, \\
& T_{m_{\min }}\left(\omega_{m}(k)\right) \leq T_{m}(k) \leq T_{m_{\max }}\left(\omega_{m}(k)\right),
\end{aligned}
$$

where $\mathrm{SOC}_{\min }(k)$ and $\mathrm{SOC}_{\text {max }}(k)$ are the minimum and maximum value of SOC, $\omega_{e_{\min }}$ and $\omega_{e_{\max }}$ refer to the minimum and maximum value of engine speed, $T_{e_{\min }}\left(\omega_{e}(k)\right)$ and $T_{e_{\max }}\left(\omega_{e}(k)\right)$ are the relevant minimum and maximum engine torque of engine speed $\omega_{e}(k), \omega_{m_{\min }}$ and $\omega_{m_{\max }}$ are the minimum and maximum value of electric motor speed, and $T_{m_{\min }}\left(\omega_{m}(k)\right)$ and $T_{m_{\max }}\left(\omega_{m}(k)\right)$ are the relevant minimum and maximum motor torque with respect to the motor speed $\omega_{m}(k)$, respectively. At stage $k$, all states of SOC within the constraints make up a set $X(k)$ which is known as the reachable set. The quantified increment of SOC is marked as $\triangle$ SOC. Then,

$$
\begin{aligned}
X(k)= & \left\{\mathrm{SOC}_{\text {min }}(k), \mathrm{SOC}_{\text {min }}(k)+\Delta \mathrm{SOC},\right. \\
& \left.\mathrm{SOC}_{\text {min }}(k)+2 \cdot \Delta \mathrm{SOC}, \ldots, \mathrm{SOC}_{\text {max }}(k)\right\} .
\end{aligned}
$$

All values of the control for $T_{m}$ within the constraints are called the admissible control set and marked as $U(k)$. The quantified increment of $T_{m}$ is marked as $\Delta T_{m}$. Then,

$$
\begin{aligned}
U(k)=\{ & T_{m_{\min }}\left(\omega_{m}(k)\right), T_{m_{\min }}\left(\omega_{m}(k)\right)+\Delta T_{m}, \\
& \left.T_{m_{\min }}\left(\omega_{m}(k)\right)+2 \cdot \Delta T_{m}, \ldots, T_{m_{\max }}\left(\omega_{m}(k)\right)\right\} .
\end{aligned}
$$

The required torque $T_{w}(k)$ and speed $\omega_{w}(k)$ of the wheel can be calculated via the future vehicle velocity $v(k)[9,13]$. For all of the reachable value of $X(k)$, the admissible set $U(k)$ of $T_{m}$ can be determined and then the equivalent fuel consumption with respect to different combination of $T_{m}$ and $T_{e}$ will be obtained by traversing all of the points in $U(k)$. Based on the above analysis, the minimum fuel consumption $J^{*}(x(k), k)$ and the optimal control signal $u^{*}(k)$ of each state in $X(k)$ can be calculated backward from the terminal condition. The above algorithm can be programmed in MATLAB, and the flow chart is shown in Figure 5. 
TABLE 1: The major parameters of plugin hybrid electric vehicle.

\begin{tabular}{|c|c|c|c|c|c|c|c|c|c|c|}
\hline \multirow[b]{2}{*}{$\begin{array}{l}\text { Vehicle } \\
\text { weight } / \mathrm{kg}\end{array}$} & \multirow[b]{2}{*}{ Final ratio } & \multicolumn{5}{|c|}{ Gear ratio } & \multirow[b]{2}{*}{$\begin{array}{l}\text { The rated power } \\
\text { of engine } / \mathrm{kW}\end{array}$} & \multirow[b]{2}{*}{$\begin{array}{l}\text { The rated power } \\
\text { of motor } / \mathrm{kW}\end{array}$} & \multicolumn{2}{|c|}{ Lithium battery } \\
\hline & & $\begin{array}{l}\mathrm{V} \\
\text { gear }\end{array}$ & $\begin{array}{l}\text { IV } \\
\text { gear }\end{array}$ & $\begin{array}{l}\text { III } \\
\text { gear }\end{array}$ & $\begin{array}{c}\text { II } \\
\text { gear }\end{array}$ & $\begin{array}{c}\text { I } \\
\text { gear }\end{array}$ & & & Capacity/Ah & $\begin{array}{l}\text { The rated } \\
\text { voltage/V }\end{array}$ \\
\hline 1129 & 1 & 2.84 & 3.77 & 5.01 & 7.57 & 13.45 & 41 & 49 & 18 & 267 \\
\hline
\end{tabular}

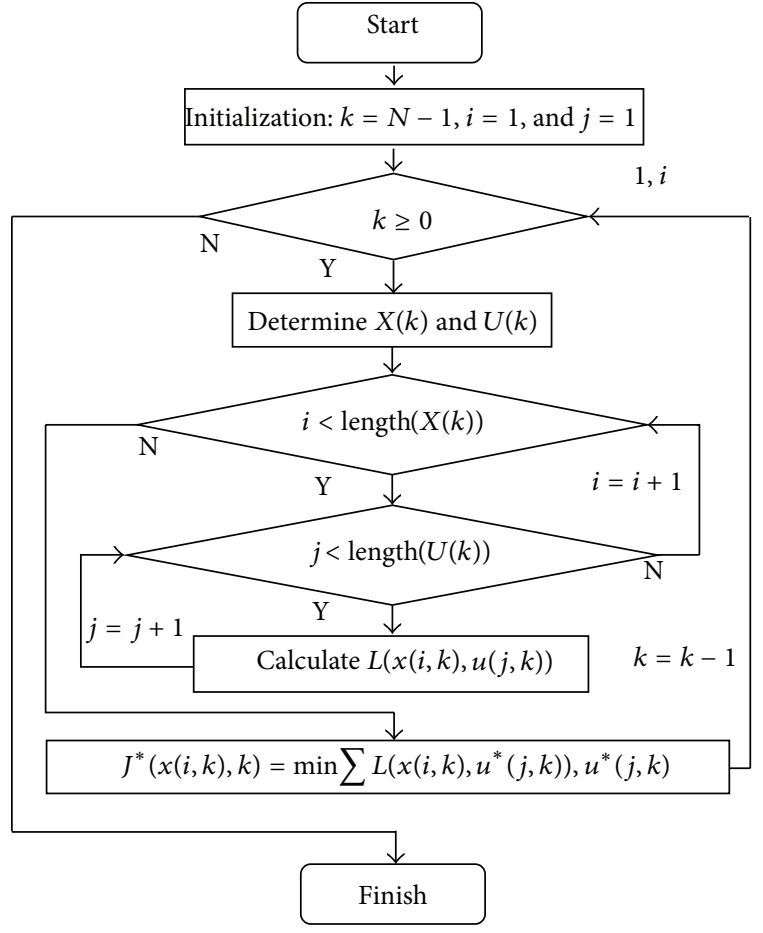

FIGURE 5: Flow chart of DP algorithm.

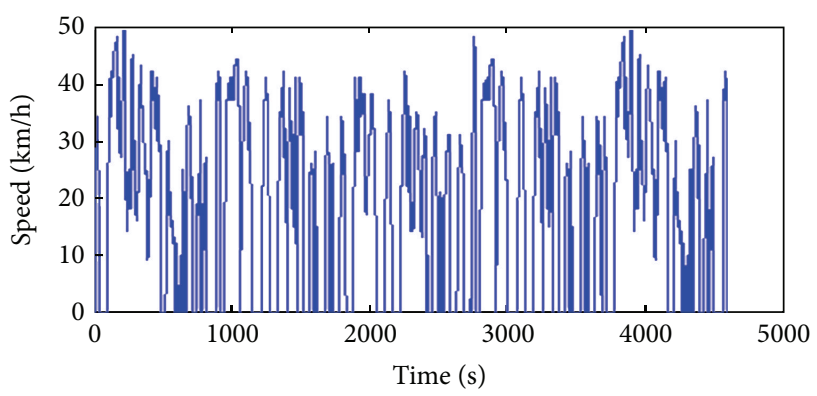

FIgURE 6: The predicted road condition.

\section{Simulation and Analysis}

In order to verify the effectiveness of the energy management strategy proposed here, the traffic data of Shandong University school bus collected in February 22, 2012, were divided into a number of individual segments, and the time-velocity curve of each segment was regarded as the predicted trip (as shown in Figure 6). The major parameters of plugin hybrid electric vehicle are shown in Table 1.

The initial value and final value of SOC were set to be 0.9 and 0.5 , respectively. $\Delta \mathrm{SOC}$ is 0.025 , and $\Delta T_{m}$ is $1 \mathrm{Nm}$. This

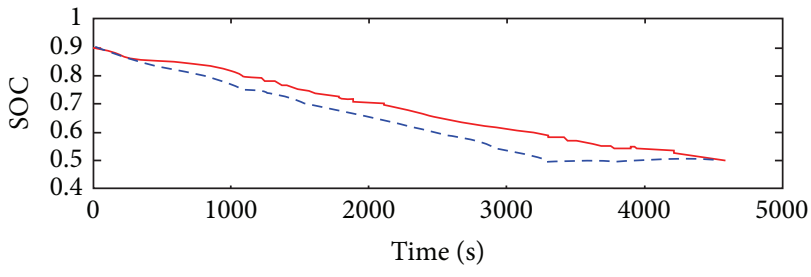

- Strategy 1
-- Strategy 2

FIgURE 7: Comparison of two SOC trajectories.

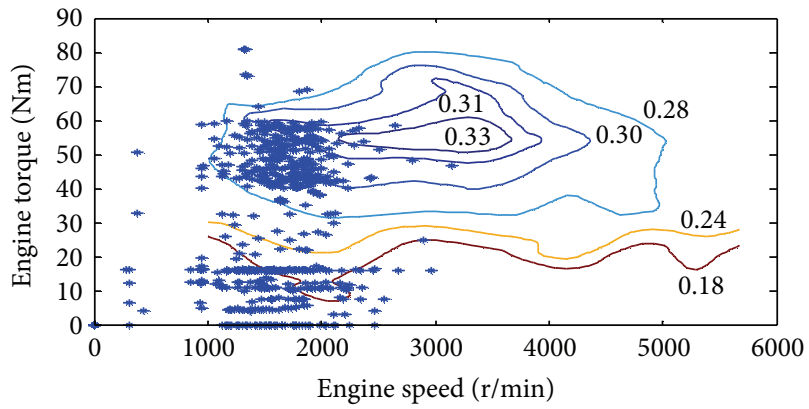

FIGURE 8: Engine operating points of strategy 1.

energy management strategy was loaded on the ADVISOR platform to test the fuel economy, and the evaluation index is fuel consumption per $100 \mathrm{~km}$.

Using the trip-based energy management strategy (strategy 1), the fuel consumption of the plugin hybrid electric vehicle was $3.92 \mathrm{~L}$ per $100 \mathrm{~km}$ when the initial value SOC was 0.9 , while the fuel consumption of the charge depletingcharge sustaining strategy (strategy 2) was 4.53 L. Compared with strategy 2, strategy 1 can improve the fuel economy for about $13.47 \%$. The comparison of SOC profiles for these two strategies is shown in Figure 7. In order to clearly see whether the engine operate in the high efficiency area, Figures 8 and 9 illustrate the engine operating points under these two strategies. The engine operating points of strategy 1 are more concentrated in high efficiency area, while those of strategy 2 distribute in the low load area where the efficiency is lower as well. It is clear that strategy 1 increases the engine working efficiency significantly, and it also means that strategy 1 has a better energy saving effect.

The simulation results of fuel consumption for different initial SOC values $(0.85,0.8$, and 0.75$)$ are shown in Table 2. Compared with strategy 2, all of the fuel economy of strategy 1 under different conditions has an increment more than $13 \%$. 
TABLE 2: Simulation results with different SOC initial values.

\begin{tabular}{lcccc}
\hline $\begin{array}{l}\text { Fuel consumption } \\
(\mathrm{L} / 100 \mathrm{~km})\end{array}$ & 0.9 & 0.85 & 0.8 & 0.75 \\
\hline Strategy 1 & 3.92 & 3.97 & 4.11 & 4.33 \\
Strategy 2 & 4.53 & 4.92 & 5.34 & 5.68 \\
\hline
\end{tabular}

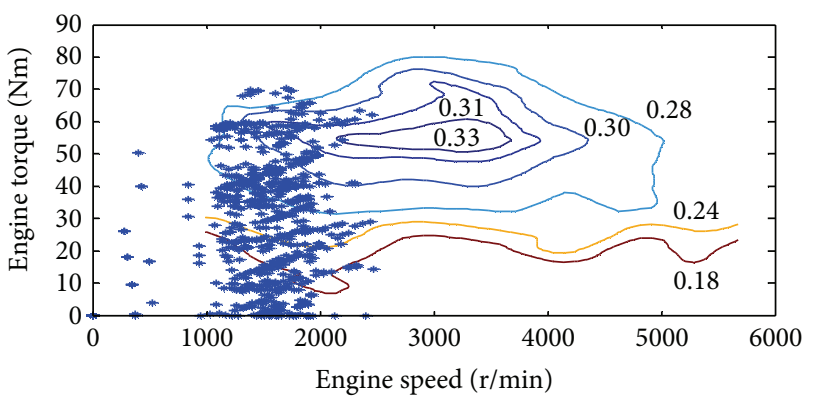

FIGURE 9: Engine operating points of strategy 2.

\section{Conclusion}

A driving cycle model is constructed by collecting and processing the driving data for the school bus of Shandong University in this paper. An energy management strategy is proposed based on the combination of the whole driving cycle condition and the segment condition between the traffic intersections. This strategy takes a highly sufficient consideration of the randomness and time-varying characteristics in the actual traffic environment. Therefore, this energy management strategy can respond to the change in real-time traffic status rapidly and will be more practical. Compared with CDCS strategy, the trip-based energy management strategy increases the fuel economy of plugin hybrid electric vehicle significantly and largely inspires its energy conservation potential. In addition, the trip modeling method in this paper is more convenient to be popularized to the trip modeling of public and company shuttle buses which have a fixed route.

\section{Conflict of Interests}

The authors declare that there is no conflict of interests regarding the publication of this paper.

\section{Acknowledgments}

The authors would like to thank the editors and referees for their thoughtful review of this paper and their insightful comments used to improve the quality of this paper. This research is supported by the National Natural Science Foundation of China (Grant nos. 61034007, 61304029, 61304033, and 61304130) and the Natural Science Foundation of Xinjiang (Grant no. 201318101-16).

\section{References}

[1] S. G. Wirasingha and A. Emadi, "Classification and review of control strategies for plug-in hybrid electric vehicles," IEEE Transactions on Vehicular Technology, vol. 60, no. 1, pp. 111-122, 2011.

[2] J. Q. Xi and Y. D. Chen, "Research on conflict decision between shift schedule and multienergy management for PHEV with automatic mechanical transmission under special driving cycles," Mathematical Problems in Engineering, vol. 2013, Article ID 517387, 8 pages, 213.

[3] Y. Deguchi, K. Kuroda, M. Shouji et al., "HEV charge/discharge control system based on navigation information," SAE Paper, vol. 3, no. 29, pp. 1-4, 2004.

[4] Q. Gong, Y. Li, and Z. Peng, "Power management of plugin hybrid electric vehicles using neural network based trip modeling," in Proceedings of the American Control Conference (ACC '09), pp. 4601-4606, June 2009.

[5] Q. Gong, Y. Li, and Z.-R. Peng, “Trip-based optimal power management of plug-in hybrid electric vehicles," IEEE Transactions on Vehicular Technology, vol. 57, no. 6, pp. 3393-3401, 2008.

[6] D. S. Zhou and X. M. Liu, Automobile Intelligent Transportation, Automobile intelligent transportation, Beijing, China, 2004.

[7] C. Zhang, A. Vahidi, P. Pisu, X. Li, and K. Tennant, "Role of terrain preview in energy management of hybrid electric vehicles," IEEE Transactions on Vehicular Technology, vol. 59, no. 3, pp. 1139-1147, 2010.

[8] D. J. Liu, The Global Positioning System (GPS) Theory and Data Processing, Tongji University press, Shanghai, China, 1997.

[9] D. A. Luo and L. Q. Liao, "Vehicular GPS coordinate transform formula and its application," Journal of Southwest Jiaotong University, vol. 36, no. 4, p. 365, 2001.

[10] M. W. Hu, "Study on GPS-based real-time traffic information collection method," Journal of Highway and Transportation Research and Development, vol. 24, no. 5, pp. 11-16, 2006.

[11] J. Shao and F. W. Meng, "Gronwall-Bellman type inequalities and their applications to fractional differential equations," Abstract and Applied Analysis, vol. 2013, Article ID 217641, 7 pages, 2013.

[12] J. Si, L. Yang et al., "Approximate dynamic programming for continuous state and control problems," in Proceedings of the 17th Mediterranean Conference on Control and Automation (MED '09), pp. 1415-1420, 2009.

[13] P. Khayyer, J. Wollaeger, S. Onori, V. Marano, Ü. Özgüner, and G. Rizzoni, "Analysis of impact factors for plug-in hybrid electric vehicles energy management," in Proceedings of the 15th International IEEE Conference on Intelligent Transportation Systems (ITSC '12), pp. 1061-1066, September 2012. 


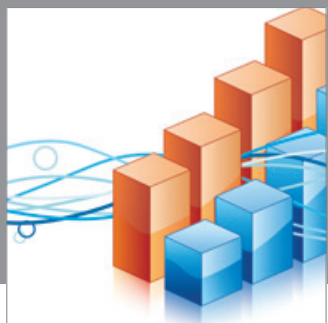

Advances in

Operations Research

mansans

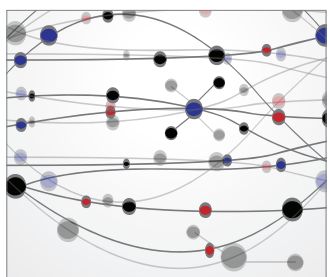

The Scientific World Journal
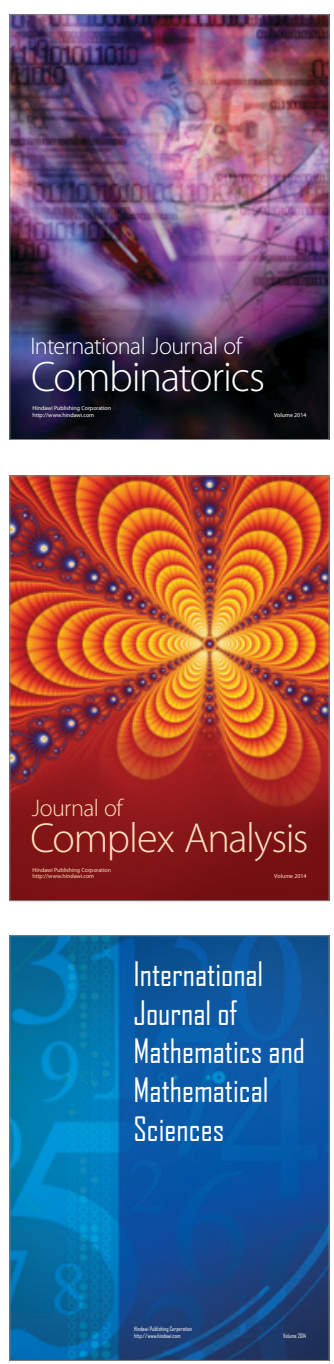
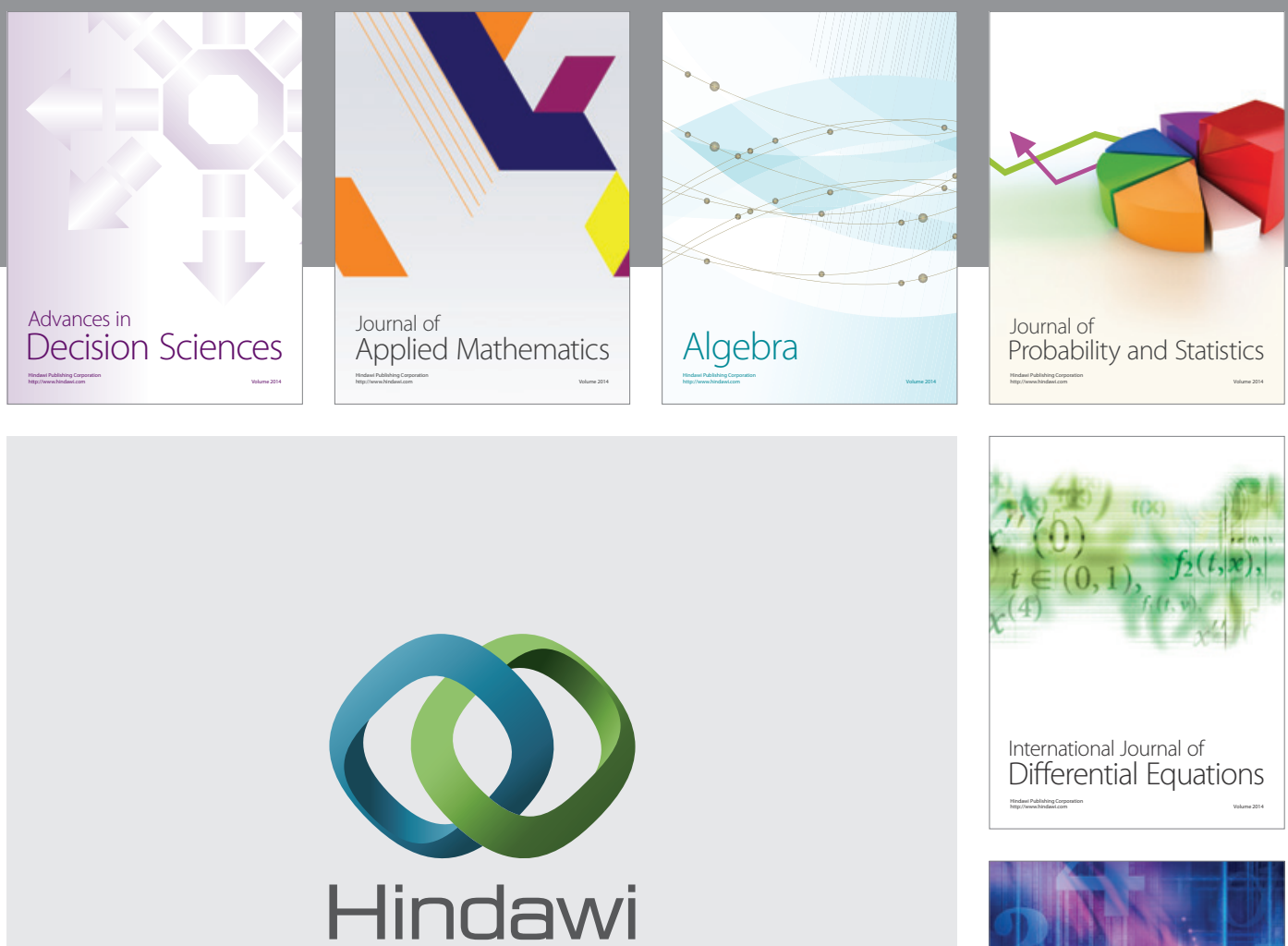

Submit your manuscripts at http://www.hindawi.com
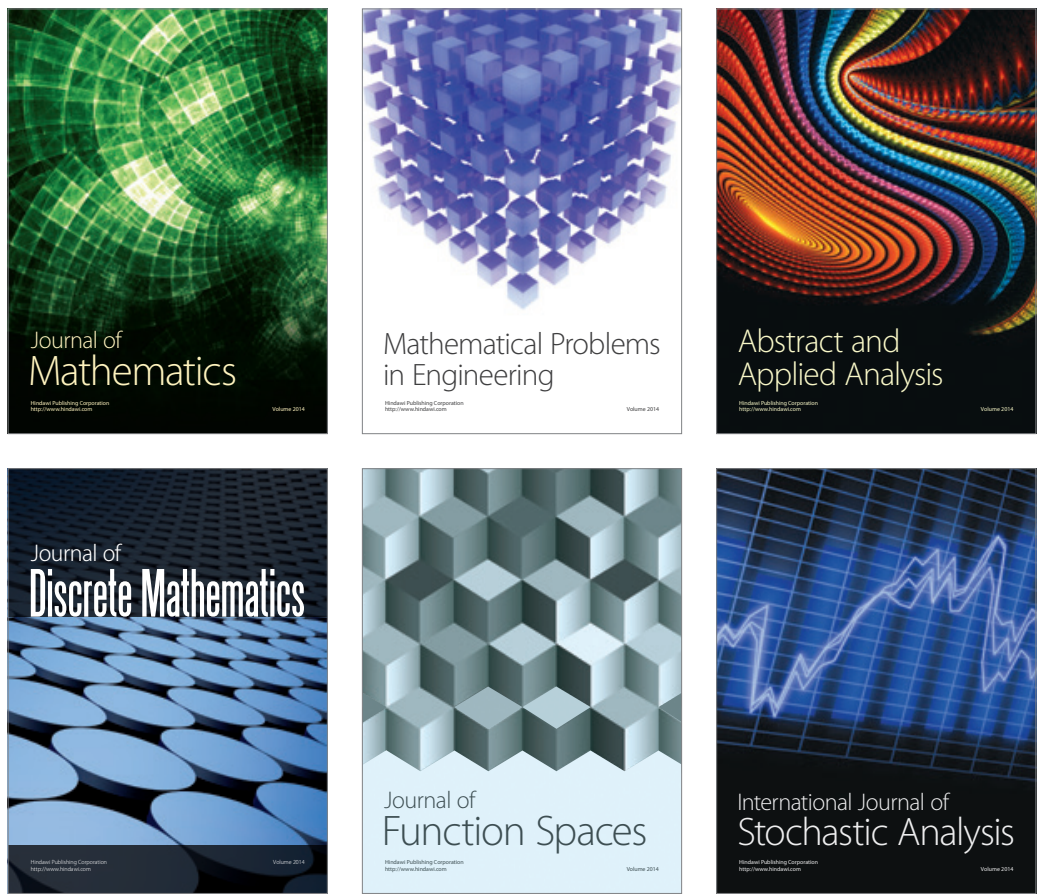

Journal of

Function Spaces

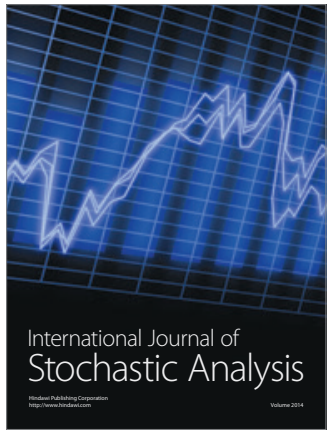

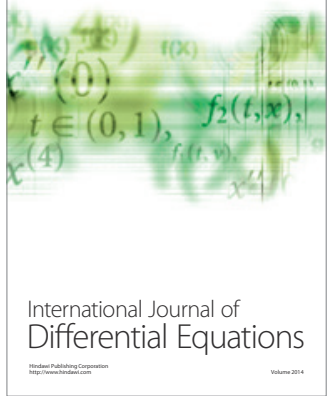
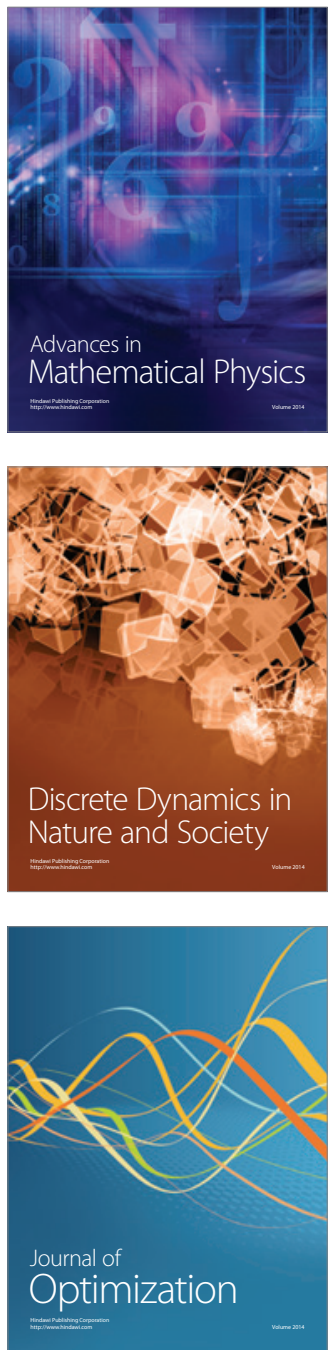